\title{
Partographic comparison of spontaneous labour with oxytocin and prostaglandin induced labour
}

\author{
Kirti M. Hurakadli* \\ Department of Obstetrics and Gynaecology, S. N. Medical College, RGUHS, Bagalkot, Bengaluru, India
}

Received: 04 January 2016

Revised: 19 June 2016

Accepted: 04 July 2016

\section{*Correspondence:}

Dr. Kirti M. Hurakadli,

E-mail: mh_kirti@yahoo.co.in

Copyright: $\odot$ the author(s), publisher and licensee Medip Academy. This is an open-access article distributed under the terms of the Creative Commons Attribution Non-Commercial License, which permits unrestricted non-commercial use, distribution, and reproduction in any medium, provided the original work is properly cited.

\begin{abstract}
Background: To study the cervimetric progress (pattern) of labor in primi gravid women with spontaneous labor and in those with labor induced with oxytocin, oral misoprostol $(25 \mu \mathrm{g})$ and vaginal misoprostol $(25 \mu \mathrm{g})$ and to suggest, one nearer the best inducing agent.

Methods: 100 primigravida women with singleton pregnancy with vertex presentation either in the latent phase of spontaneous labor or having an indication for induction were included in this study. They were divided into four equal groups of 25 each, and induced with oral misoprotol $(25 \mu \mathrm{g})$, vaginal misoprostol $(25 \mu \mathrm{g})$ and oxytocin. Fourth group was allowed for spontaneous labor. Main outcome measures studied were Success rate. Induction - delivery interval, mode of delivery and maternal and fetal complications. The quantitative data, comparison was performed using the chi-square test with Yates's correction, students ' $t$ ' test and analysis of variation. Group averages were reported as mean \pm standard deviation.

Results: Mean induct ion delivery interval was significantly shorter in the oxytocin group and oral misoprostol. The pattern of cervical dilation in the oral misoprostol group closely followed the partographic curve of spontaneous labor. Cesarean rates were higher in the oxytocin group when compared to oral and vaginal misoprostol group.

Uterine tachysystole was seen in 2 cases of oxytocin group when compared to one case in the vaginal misoprostol group.

Conclusions: Oxytocin was a better inducing agent with respect to shorter induction to delivery time, maternal complications. Oral misoprostol showed a lot of promise in the dosage and frequency used the ease of administration, success rate, and fewer perinatal and maternal complications.
\end{abstract}

Keywords: ACOG, Induction of labour, Bishop score, PROM, Misoprostol

\section{INTRODUCTION}

More than $22 \%$ of all gravid women undergo Induction of labor in the US and the overall rate of induction of labor in the US has more than doubled since 1990 to $225 / 1000$ live births in $2006 .^{1}$

The goal of induction of labor (IOL) is to achieve vaginal delivery by stimulating uterine contractions before the onset of labor. Generally, IOL has merit as a therapeutic option when the benefits of expediting the delivery outweigh the risk of continuing the pregnancy. The benefits of IOL must be weighed against the potential maternal and fetal risks associated with this procedure. ${ }^{1}$

The ability to induce labor safely and efficiently is one of the most important developments in obstetrics during the 2nd half of this century. ${ }^{2}$ Despite the advances in basic knowledge, we have not come far in providing our obstetrician with safe, reliable and cost effective methods to induce labor with subsequent vaginal delivery. Oxytocin and prostaglandins are released during labor as 
a normal physiologic process. Hence we have attempted to study these agents in detail. ${ }^{3}$

The development of safe and effective regimen for oxytocin administration has provided long desired control of the onset of labor. Despite the continued fine tuning of the administration of oxytocin, however familiarity, safety and reliability has maintained oxytocin as the agent of choice to induce labor. The major deficiency of oxytocin to induce labor is a high failure rate in women with lower cervical scores and this has led to the search of other agents and methods of labor induction. ${ }^{3}$

Prostaglandins have achieved considerable attention when used to help begin induction in women with unfavourable cervices. Prostaglandins are considered to be directly involved in the initiation of labor. In term patients with an unfavourable cervix and an inactive myometrium, it seems logical to use prostaglandins to ripen the cervix or induce labor or both. ${ }^{4}$

Induction of labour as defined by various authors is given below:

Stimulation of uterine contractions before spontaneous onset of labour with or without ruptured membranes. ${ }^{5}$

Artificial termination of pregnancy any time after 28 weeks of gestation by a method that aims to secure delivery per via naturalis whether or not the intention is fulfilled is not included in this definition. ${ }^{6}$

According to ACOG 2009 - Goal of IOL is to achieve vaginal delivery by stimulating uterine contractions before the spontaneous onset of labour. ${ }^{1}$

Non spontaneous initiation of uterine contractions that results in progressive cervical effacement and dilatation with descent of the presenting part to achieve vaginal delivery when continuation of pregnancy presents a threat to the life or well-being of the mother or her unborn child. $^{7}$

Incidence varies in different institutions but generally showing a rising trend. There is wide variation of opinion on the indication, results and prognosis of induction of labour. ${ }^{8}$

Induction of labour is indicated in medical, obstetric, and foetal conditions in which prolongation of pregnancy would jeopardize maternal and foetal well-being and in which there are no contra-indications to the use of oxytocin and prostaglandins. ${ }^{9}$

Indications for induction of labour as per ACOG guidelines 20091 are:

- Abruptio placenta

- Chorioamnionitis

- Fetal demise
- Gestational hypertension

- Preeclampsia, eclampsia

- Premature rupture of membranes

- Postterm pregnancy

- Maternal medical conditions (eg, diabetes mellitus, renal disease, chronic pulmonary disease, chronic hypertension, antiphospholipid syndrome).

- Fetal compromise (eg, severe fetal growth restriction, isoimmunization, oligohydramnios).

- Logistic reasons
a. Risk rapid labour
b. History rapid labour
c. Distance from the hospital
d. Psychosocial indication

Contraindications for induction of labour as per ACOG guidelines 2009 are: ${ }^{1}$

- Placenta or vasa previa

- Abnormal foetal lie

- Cord presentation

- Prior classical uterine incision

- Prior myomectomy or uterine unification surgery entering the endometrial cavity

- Active genital herpes infection

- Invasive cervical carcinoma.

Assessment of gestational age and consideration of any potential risks to the mother or fetus are of paramount importance for appropriate evaluation and counseling before initiating cervical ripening or labor induction. The patient should be counselled regarding the indications for induction, the agents and methods of labor stimulation, and the possible need for repeat induction or caesarean delivery. Although prospective studies are limited in evaluating the benefits of elective induction of labor, nulliparous women undergoing induction of labor with unfavourable cervices should be counselled about a twofold increased risk of caesarean delivery. In addition, labor progression differs significantly for women with an elective induction of labor compared with women who have spontaneous onset of labor. Allowing at least 12-18 hours of latent labor before diagnosing a failed induction may reduce the risk of caesarean delivery. ${ }^{1}$

\section{Confirmation of Term gestation ${ }^{1}$}

- Ultrasound measurement at less than 20 weeks of gestation supports gestational age of 39 weeks or greater

- Fetal heart tones have been documented as present for 30 weeks by Doppler ultrasonography

- It has been 36 weeks since a positive serum or urine human chorionic gonadotropin pregnancy test result.

At least one of the gestational age criteria in the box should be met, or fetal lung maturity should be established. A mature fetal lung test result before 39 
weeks of gestation, in the absence of appropriate clinical circumstances, is not an indication for delivery. ${ }^{1}$

Additional requirements for cervical ripening and induction of labor include assessment of the cervix, pelvis, fetal size, and presentation. Monitoring FHR and uterine contractions is recommended as for any high risk patient in active labor. Although trained nursing personnel can monitor labor induction, a physician capable of performing a caesarean delivery should be readily available. ${ }^{1}$

\section{Predictors of successful induction ${ }^{10}$}

Because of the risk of failed induction of labour, a variety of maternal and fetal factors as well as screening tests have been suggested to predictor labour induction success.

\section{Maternal factors - parity}

- Body mass index

- Cervical status - bishop score

- Transvaginal ultrasound

Fetal factors - birth weight

- Gestational age

Biochemical - fetal fibronectin (FFN)

- Insulin like growth factor

Parous, young women who are taller and lower weight have a higher rate of induction success (IS).

Fetuses with a lower birth weight or increased gestational age are also associated with increased success rated.

The condition of the cervix at the start of induction is an important predictor, with the modified Bishop score being a widely used scoring system. The most important element of the bishop score is dilatation.

Other predictors including TVUS and biochemical markers (including FFN) have been suggested, but to date they have not been shown to be superiors to Bishop score. Further research is needed to evaluate these potential predictors and IGFBP-1 - another potential biochemical marker.

\section{Bishop score si $^{13}$}

Bishop score is the most prevalent scoring system for pre-induction cervical assessment. This system and its many modifications take into account the cervical dilatation, effacement, consistency and position and the station of the presenting part. Cervical dilatation is the factor with the strongest association with successful induction.
Table 1: Burnetts modification of the bishop score is as follows.

\begin{tabular}{|lllc|}
\hline \multirow{2}{*}{ Factors } & $\mathbf{3}$ & $\mathbf{1}$ & \multicolumn{1}{c|}{ Score } \\
\hline Dilatation & $<1.5$ & $1.5-3$ & $>3$ \\
\hline Station & $-2 /$ higher & -1 & 0 or lower \\
\hline Position & Posterior & Mid & Anterior \\
\hline Effacement & $\geq 1.5 \mathrm{~cm}$ & Intermediate & $<0.5$ \\
\hline Consistency & firm & Intermediate & Soft \\
\hline
\end{tabular}

Maximum score is 10 .

A score of more than 6 is a favourable score with a predictable outcome.

The main of this study was to review current methods for cervical ripening, and IOL, to the pattern of induced labor and compare it with patterns of spontaneous labor to derive at the best possible inducing agent.

\section{METHODS}

\section{Source of data}

Pregnant women admitted to our hospital over a period of ranging from November 2010 to October 2012 were recruited for the study.

\section{Method of collection}

With informed-written consent, one hundred pregnant women were selected at random and were divided into four equal groups.

- Labor induced with oral misoprostol alone

- Labor induced with vaginal misoprostol alone

- Labor induced with IV Oxytocin(high dose protocol) alone

- Latent phase of spontaneous labor.

Selection of candidates was made using inclusion and exclusion criteria as follows.

\section{Inclusion criteria}

Primigravida with singleton vertex presenting pregnancy, either in latent phase of spontaneous labor or having an indication for induction of labor as laid down in the ACOG practice bulletin 114, 2009. ${ }^{1}$

- Abruption placenta

- Chorioamnionitis

- Fetal demise

- Gestational hypertension

- Pre-eclampsia, eclampsia

- Post term pregnancy

- PROM 
Maternal medical conditions (e.g., diabetes mellitus, renal disease, chronic pulmonary disease, chronic hypertension, anti-phospholipid syndrome).

Fetal compromise (e.g., severe growth retardation, isoimmunization, oligohydraminos). Logistic reasons risk of rapid labor, history of rapid labor, distance from the hospital, psychosocial indication

\section{Exclusion criteria}

Pregnant women having a contraindication for induction of labor as per ACOG practice bulletin 114, were excluded. ${ }^{1}$ Also excluded were the patients in whom there was a medical contraindication for oxytocin or prostaglandins.

- Placenta previa

- Abnormal fetal lie

- Cord presentation

- Prior classical uterine incision

- Prior myomectomy or uterine unification surgery entering the endometrial cavity

- Active genital herpes infection

- Invasive cervical carcinoma.

\section{Protocol for induction of labor with oral misoprostol}

Induction with oral misoprostol was started with the initial dose of 25 micrograms. Dosage was repeated every 4 hours until an adequate contraction pattern was set in.

Maximum allowable doses were six (150 micrograms of the drug). If labor did not ensue, even after 4 hours following last dose, it was considered as failed induction.

\section{Protocol for induction of labor with vaginal misoprostol}

Patients assigned to the intra-vaginal misoprostol group had 25micrograms inserted into the posterior fornix of the vagina. If patient failed to get adequate contractions, and the Bishop's score was <6, misoprostol administration was repeated every 4 hours. The maximal dose of misoprostol was 150 micrograms (6 doses).

\section{Protocol for induction of labor with oxytocin}

Oxytocin was delivered in a high dose manner according to arithmetic escalation protocol. The infusion rate was begun at 5 milli units/minute and increased in 5 milli units/minute, increments every 30 minutes depending on the frequency and strength of contractions. Maximum dose allowed was 40 milli units per minute. Cervical examination was performed every two hours after starting induction and whenever clinically indicated.

\section{Recording of progress in labor}

In all patients, the cervical status is assessed by using Bishop's score prior to induction and then every 4-6 hours. A score of more than 6 is a favorable score with a predictable outcome. Fetal heart rate was recorded half hourly.

\section{Statistical analysis}

The quantitative data, comparison was performed using the chi-square test with Yates's correction, students" test and analysis of variation. Group averages were reported as mean \pm standard deviation.

\section{RESULTS}

Table 2: Indication for induction.

\begin{tabular}{|llll|}
\hline Indications & Oral misoprostol & Vaginal misoprostol & Oxytocin \\
\hline PROM & 8 & 7 & 17 \\
\hline PD & 7 & 8 & 3 \\
\hline PE & 6 & 6 & 1 \\
\hline IUD & 4 & 4 & $\mathbf{2 5}$ \\
\hline Total & $\mathbf{2 5}$ & $\mathbf{2 5}$ & \\
\hline
\end{tabular}

$\mathrm{X} 2=10.26, \mathrm{P}=0.12$, Not significant.

Table 3: Induction - delivery interval.

\begin{tabular}{|c|c|c|c|}
\hline I-D Interval (min) & $\begin{array}{l}\text { Oral misoprostol } \\
(n=24) N(\%)\end{array}$ & $\begin{array}{l}\text { Vaginal misoprostol } \\
(\mathbf{n = 2 3}) \quad \mathrm{N}(\%)\end{array}$ & $\begin{array}{l}\text { Oxytocin } \\
(n=20) N(\%)\end{array}$ \\
\hline 300-480 5-8 Hours & $2(8)$ & $1(4)$ & $2(10)$ \\
\hline 481-720 8-12 Hours & $10(42)$ & $5(22)$ & $7(35)$ \\
\hline 721-960 12-16 Hours & $6(25)$ & $5(22)$ & $8(40)$ \\
\hline 961-1440 16-24 Hours & $6(25)$ & $8(35)$ & $3(15)$ \\
\hline 1441-2250 24-38 Hours & - & $4(17)$ & - \\
\hline Mean \pm Sd & $803 \pm 277$ & $1080 \pm 510$ & $735 \pm 238$ \\
\hline Range & $300-1410$ & $580-\overline{2250}$ & $390-1200$ \\
\hline
\end{tabular}

$\mathrm{F}=5.56, \mathrm{P}<0.05$, significant. 
Table 4: Change in bishop score.

\begin{tabular}{|llll|}
\hline $\begin{array}{l}\text { Change in Bishop } \\
\text { score }\end{array}$ & $\begin{array}{l}\text { Oral misoprostol } \mathbf{N} \\
(\%)\end{array}$ & $\begin{array}{l}\text { Vaginal misoprostol } \mathbf{N} \\
(\%)\end{array}$ & Oxytocin $\mathbf{N}(\%)$ \\
\hline Less than 3 & $8(32)$ & $10(40)$ & $8(32)$ \\
\hline $3-6$ & $17(68)$ & $13(52)$ & $10(40)$ \\
\hline More than 6 & - & $2(8)$ & $7(28)$ \\
\hline Total & $\mathbf{2 5}$ & $\mathbf{2 5}$ & $\mathbf{2 5}$ \\
\hline
\end{tabular}

$\mathrm{X} 2=10.82, \mathrm{P}<0.05$.

Table 5: Duration of latent phase, active phase and total duration of labor.

\begin{tabular}{|c|c|c|c|}
\hline \multirow[t]{2}{*}{ Groups } & \multicolumn{3}{|c|}{ Mean duration (minutes) } \\
\hline & $\begin{array}{l}\text { Latent } \\
\text { phase }\end{array}$ & $\begin{array}{l}\text { Active } \\
\text { phase }\end{array}$ & $\begin{array}{l}\text { Total } \\
\text { duration }\end{array}$ \\
\hline $\begin{array}{l}\text { Oral } \\
\text { misoprostol }\end{array}$ & 393.7 & 236.7 & 630.4 \\
\hline $\begin{array}{l}\text { Vaginal } \\
\text { misoprostol }\end{array}$ & 420.8 & 325.4 & 746.2 \\
\hline Oxytocin & 317.6 & 316.7 & 634.3 \\
\hline Spontaneous & 204.0 & 341.2 & 545.2 \\
\hline
\end{tabular}

Table 6: Mode of delivery.

\begin{tabular}{|lclll|}
\hline Groups & $\begin{array}{l}\text { Normal } \\
(\%)\end{array}$ & $\begin{array}{l}\text { Instrumental } \\
(\%)\end{array}$ & $\begin{array}{l}\text { LSCS } \\
(\%)\end{array}$ & Total \\
\hline $\begin{array}{l}\text { Oral } \\
\text { misoprostol }\end{array}$ & $22(88)$ & $2(8)$ & $1(4)$ & 25 \\
\hline $\begin{array}{l}\text { Vaginal } \\
\text { misoprostol }\end{array}$ & $19(76)$ & $4(16)$ & $2(8)$ & 25 \\
\hline $\begin{array}{l}\text { Oxytocin } \\
\text { Spontaneous }\end{array}$ & $15(60)$ & $5(20)$ & $5(20)$ & 25 \\
\hline $\mathrm{X} 2=12.92, \mathrm{P}=0.17$. & $4(16)$ & - & 25 \\
\hline
\end{tabular}

\section{DISCUSSION}

In our study, Oral misoprostol showed a lot of promise in the dosage and frequency used similar to study by Alfirevic et al. ${ }^{11}$ It had the desired effect in inducing contraction early and the ease of administration, success rate, and fewer perinatal and maternal complications.
Vaginal misoprostol did not fare well as an inducing agent with a longer induction to delivery time, longer first stage and second stage.

Table 7: Perinatal outcome.

\begin{tabular}{|llll|}
\hline $\begin{array}{l}\text { Perinatal } \\
\text { outcome }\end{array}$ & $\begin{array}{l}\text { Oral } \\
\text { misoprostol } \\
\text { N } \%)\end{array}$ & $\begin{array}{l}\text { Vaginal } \\
\text { misopros- } \\
\text { tol N }(\%)\end{array}$ & $\begin{array}{l}\text { Oxytoc } \\
\text { in }\end{array}$ \\
\hline $\begin{array}{l}\text { Birth wt } \\
\text { (gms) mean }\end{array}$ & 2624 & 2634 & 2649 \\
\hline Apgar at 1 & 6.2 & 6.0 & 6.3 \\
\hline Apgar at 5 & 8.0 & 8.1 & 7.9 \\
\hline Apgar <7 at 5 & $4(16)$ & $1(4)$ & $9(36)$ \\
\hline Meconium & - & $2(8)$ & $4(16)$ \\
\hline Resuscitation & $2(8)$ & $2(8)$ & $2(8)$ \\
\hline $\begin{array}{l}\text { NICU } \\
\text { admission }\end{array}$ & $3(12)$ & $2(8)$ & $4(16)$ \\
\hline
\end{tabular}

We observed that oxytocin caused shorter induction to delivery time, shorter first and second stage, and less maternal complications but with more perinatal complications. Oxytocin administration could be halted at any time and then again restarted. In addition, with the half-life of oxytocin being in minutes the dosage and frequency could be easily controlled. However, oxytocin was an invasive procedure, costlier and caused restricted ambulation of the patient, similar to a study by AbdelAleem H. ${ }^{12}$

In spite of the efforts of this study, it had its shortcomings. We had compared three inducing agents simultaneously which made it not only difficult to compare the data with other studies done on induction of labor.

Table 8: Maternal complications.

\begin{tabular}{|llll|}
\hline Complication & Oral misoprostol & Vaginal misoprostol & Oxytocin N \\
\hline Cervical tear & $(\%)$ & $(\%)$ & $2(8)$ \\
\hline Tachysystole & $1(4)$ & $1(4)$ & $2(8)$ \\
\hline Postpartum hemorrhage & - & $1(4)$ & - \\
\hline Vaginal wall tear & $1(4)$ & - & $1(4)$ \\
\hline Prolonged 3 & - & - & - \\
\hline Total & - & $1(4)$ & $\mathbf{5}(\mathbf{2 0})$ \\
\hline
\end{tabular}


We had not used tocodynamometry for recording the contractions of the uterus, hence sub-clinical hyper stimulation were missed.

To evaluate the efficacy of any induction protocol for patients with unfavorable cervices, null parity is one of the main considerations in our study.

One of the drawbacks of this study was that the observer responsible for selection and intra-partum management were not blinded to the study.

We had in our study, a number of indications for induction and to study the potentially significant differences in the various characteristics in each of these indications, would require a larger study group. It would be advisable to have efficacy of the inducing agent compared for the same indications for induction.

\section{CONCLUSION}

Oxytocin was a better inducing agent with respect to shorter induction to delivery time, maternal complications. Oral misoprostol showed a lot of promise in the dosage and frequency used the ease of administration, success rate, and fewer perinatal and maternal complications.

Funding: No funding sources Conflict of interest: None declared

Ethical approval: The study was approved by the Institutional Ethics Committee

\section{REFERENCES}

1. American College of Obstetrician and Gynecologists. Induction of labor. ACOG Practice Bulletin 107. 2009;114(1):386-97.
2. Biswas A. Induction of labor: recent trends. Chapter2 , in recent advances on obstetrics and gynecology, New Delhi: Das Gupta S. Jaypee Brothers; 1999:1331.

3. Obrien WF, Knuppel RA. Plasma prostaglandin metabolites levels after use of prostaglandin E2 gel for cervical ripening. Am J Obstet Gynecol. 1986;155:1037.

4. Chassas MJ. The induction of labour and termination of pregnancy in Munro Kerr's operative obstetrics. $7^{\text {th }}$ Ed., Baltimore: William and Wilkins; 1964:63669.

5. Cunningham. Dystocia: abnormalities of the expulsive forces. Chapter-18, In: Williams obstetrics. $20^{\text {th }}$ Ed. Appleton and Lange; 1997:426.

6. Ian D. Induced labour. Chapter-16, In: practice obstetric problems. $5^{\text {th }}$ Ed. Lloyal-Luke; 1979:480.

7. Biswas A, Arulkumaran SG. Induction of labour. Chapter-14, In: the management of labour. Arulkumaran SG, Orient Longman; 1996:213.

8. Daftary SN. Abnormal labour. In: Holland and Brews manual of obstetrics. $16^{\text {th }}$ Ed. New Delhi : B.I. Churchill Livingstone; 1998:234.

9. Xenakis MJ. Induction of labour in the nineties: conquering the unfavourable cervix. Obstet Gynecol. 1993;90:235-9.

10. Joan MG, Crane. Factors predicting labour induction success: a critical analysis. Clin Obstet and Gynecol. 2006;49(3):573-84.

11. Alfirevic. Oral misoprostol for induction of labor. Cochrane Database Syst Rev. 201413;(6):CD001338.

12. Abdel-Aleem H. Misoprostol for cervical ripening and induction of labour: RHL commentary. The WHO Reproductive Health Library; Geneva: World Health Organization; 2011.

Cite this article as: Hurakadli KM. Partographic comparison of spontaneous labour with oxytocin and prostaglandin induced labour. Int J Reprod Contracept Obstet Gynecol 2016;5:2581-6. 